\title{
How does microRNA modulate Wnt/ $\beta$-catenin signaling in thyroid oncogenesis?
}

\author{
Cesar Seigi Fuziwara, Edna Teruko Kimura
}

Department of Cell and Developmental Biology, Institute of Biomedical Sciences, University of São Paulo, São Paulo, Brazil Correspondence to: Edna Teruko Kimura, MD, PhD. Department of Cell and Developmental Biology, Institute of Biomedical Sciences, University of São Paulo, Av. Professor Lineu Prestes, 1524, room 414, CEP 05508-000, Butantã, São Paulo-SP, Brazil. Email: etkimura@usp.br.

Provenance and Peer Review: This article was commissioned by the Editorial Office, Annals of Translational Medicine. The article did not undergo external peer review.

Comment on: Yu S, Cao S, Hong S, et al. miR-3619-3p promotes papillary thyroid carcinoma progression via Wnt/ $\beta$-catenin pathway. Ann Transl Med 2019;7:643.

Submitted Feb 07, 2020. Accepted for publication Feb 28, 2020.

doi: 10.21037/atm.2020.02.152

View this article at: http://dx.doi.org/10.21037/atm.2020.02.152

Predicting the evolution of papillary thyroid cancer (PTC), the most common type of thyroid cancer is a current challenge for cancer management. PTC usually shows good prognosis; nevertheless, a small fraction of PTC patients will exhibit aggressive radioactive-iodine refractory tumors with a poor prognosis.

MicroRNAs (miRNAs) are class of endogenous small non-coding RNAs commonly deregulated in cancer, which became hallmarks for diagnosis and prognosis of cancer (1). One of the main function of miRNAs is to inhibit the translation of target mRNA by binding to 3'-UTR region, reducing protein levels. One single miRNA may control several hundreds of targets at once, and thus, this mechanism of action results in a broad and complex effect in different signaling pathways involved in the oncogenesis and tumor progression (2). In the current issue, Yu et al. (3) describe a novel association of high expressed miRNA $m i R-3619-3 p$ in PTC with tumor progression through Wnt signaling. High levels of $m i R-3619-3 p$ in PTC positively correlated with characteristics of invasive potential such as extrathyroidal invasion, multicentricity and lymphnode metastasis.

The $m i R-3619-3 p$ is poorly conserved among mammal species and the target prediction by TargetScan algorithm (4) extended to more than 2,000 potential mRNA controlled by $m i R-3619-3 p$. $\beta$-catenin (CTNNB1), a component of the canonical Wnt signaling pathway, is among the top 10 predicted targets. Interestingly, overexpression of $m i R$ $3619-3 p$ in human thyroid cancer cell line did not reduce $\beta$-catenin protein levels as expected but enhanced CTNNB1 mRNA half-life and protein levels demonstrated by the $\mathrm{Yu}$ et al. (3). Moreover, knock-down of miR-3619-3p reduced $\beta$-catenin in PTC cell lines. Either, miR-3619-3p is acting through an unconventional and less frequent mechanism or there is an indirect effect on other proteins that led to $\beta$-catenin mRNA stabilization.

Wnt signaling is involved in developmental and physiological processes (5), and consequently altered signaling transduction may result in pathological conditions such as cancer. Indeed, Wnt signaling is altered in several types of cancer and is associated with metastasis (6). In thyroid cancer, Wnt is also deregulated (7) and some studies have shown the involvement of Wnt signaling in thyroid specification and thyroid cell differentiation control $(8,9)$. Alteration in Wnt signaling expression pattern leads to thyroid specification and morphogenesis defects in zebrafish (8).

The canonical Wnt signaling depends on the control of $\beta$-catenin levels. In the absence of signal, free $\beta$-catenin (not bound to E-cadherin) is constantly targeted to degradation by the destruction complex composed of scaffold proteins APC and Axin, and CKI and GSK3 $\beta$ which phosphorylate $\beta$-catenin. This leads to recruitment of $\beta$-TrCP, a ubiquitin E3 ligase that ubiquitinates $\beta$-catenin addressing it for proteasomal degradation (Figure 1). Wnt signaling cascade is activated upon binding of Wnt to Frizzled (FZD) and LRP5/6 co-receptors that recruits Dishevelled (DSV) and APC protein, disrupting $\beta$-catenin degradation complex and leading to $\beta$-catenin accumulation in the cytoplasm. Then, 


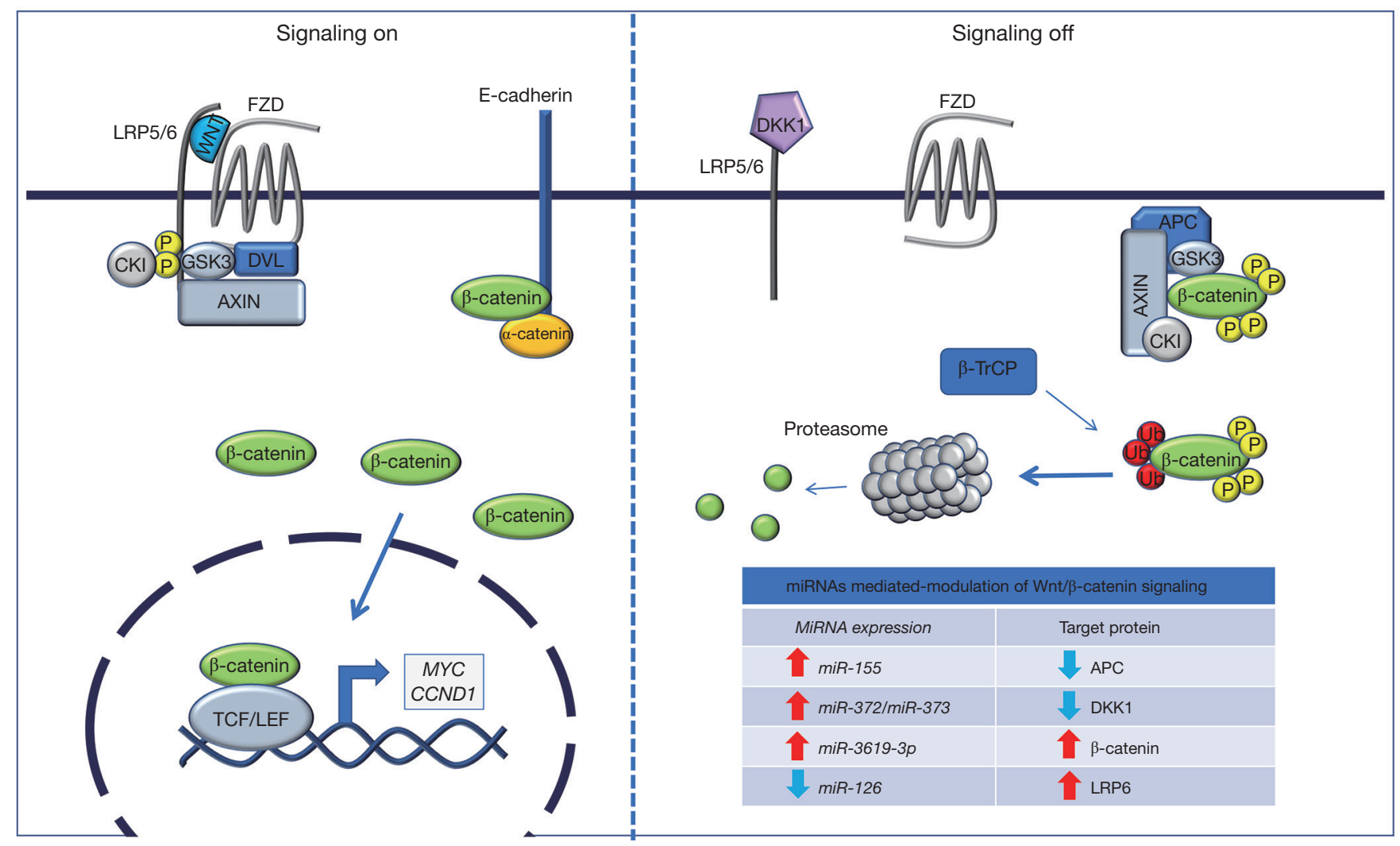

Figure 1 Canonical $W n t / \beta$-catenin signaling depends on the control of $\beta$-catenin degradation and translocation to the nucleus to activate target genes transcription. Deregulation of microRNAs that control key signaling components of Wnt/ $\beta$-catenin pathway is observed in thyroid cancer. NT, normal thyroid.

$\beta$-catenin translocates to the nucleus and forms a complex with TCF/LEF to promote the expression of target genes such as cyclinD1 (CCND1) and MYC. Dickkopf-1 (Dkk1) is an negative regulator of Wnt signaling as it binds to LRP5/6 receptors and block the formation of LRP5/6Wnt-FZD complex (Figure 1).

Several studies have shown that miRNA-mediated regulation of Wnt signaling is altered in thyroid cancer. In PTC, high levels of miR-155 target APC, a component of destruction complex (10). Overexpression of $m i R$ 155 leads to cell proliferation and activation of $\beta$-catenin signaling targets in vitro and tumor growth in vivo using a xenograft model. On the other hand, low levels of $m i R$ 126 are detected in PTC in association with poor prognosis such as LN metastasis, tumor size and stage, leading to overexpression of its target LRP6, a coreceptor for Wnt signaling (11). Additionally, $\beta$-catenin signaling can induce miRNA deregulation. Activation of $\beta$-catenin signaling induces the transcription of $m i R-371 / m i R-373 / m i R-373$ cluster (12). These miRNAs $m i R-372$ and $m i R-373$ down- regulate DKK1 by the binding to mRNA 3'-UTR, and consequently enhancing $\beta$-catenin signaling in a feedback loop. High levels of $m i R-372$ are detected in PTC and correlates with tall-cell variant that frequently is more aggressive and shows relapse (13).

Recently, high-throughput screening has shown that additional genetic alterations are important to thyroid cancer progression $(14,15)$. In anaplastic thyroid cancer, the most lethal form of thyroid cancer, mutations in $\beta$-catenin, Axin1 and APC are frequent and seems to be mutually exclusive $(16,17)$, leading to nuclear accumulation of $\beta$-catenin, a common observation by immunohistochemistry (IHC). Moreover, there is a cross-talk with the tumorsuppressive pathway of p53 (18). Active p53 down-regulates $\beta$-catenin levels by enhancing degradation process via GSK3 $\beta$ and proteasome. However, in mutant inactive p53 cells $\beta$-catenin degradation is blocked, or when $\beta$-catenin gene is mutated cells becomes resistant to $\mathrm{p} 53$-induced degradation of $\beta$-catenin (18). This cross-talk indicates that the presence of TP53 gene mutations which is a hallmark 

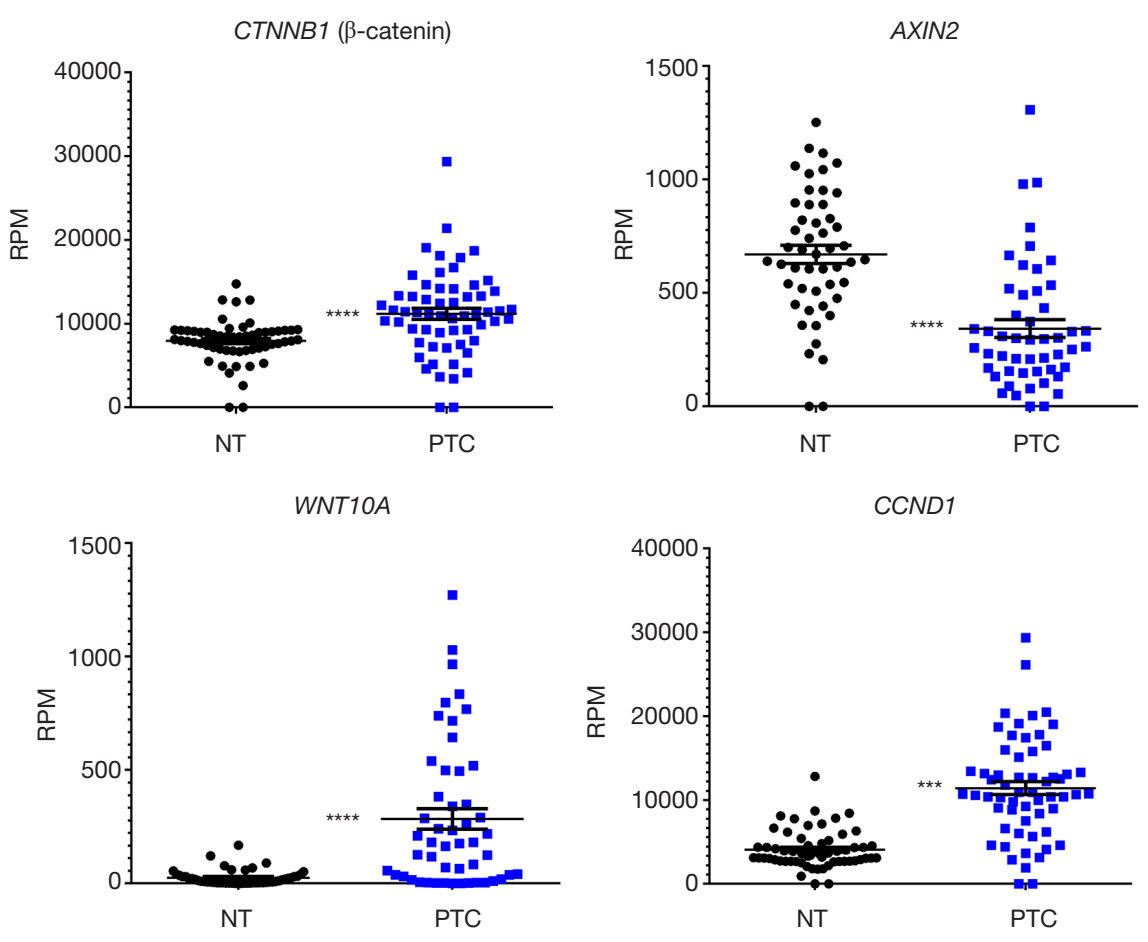

Figure 2 Gene expression of Wnt/ $\beta$-catenin signaling genes in PTC extracted from TCGA database. Fifty paired-matched non-tumoral and PTC samples. Data expressed as reads per million (RPM). ${ }^{* * *}, \mathrm{P}<0.001$; **** $\mathrm{P}<0.0001$ vs. NT using Mann-Whitney test. PTC, papillary thyroid cancer; TCGA, The Cancer Genome Atlas; NT, normal thyroid.

of ATC, being detected in up to $73 \%$ of the patients using high-throughput sequencing (14), could help to enhance $\beta$-catenin accumulation in aggressive thyroid cancer. These observations point an important role of $\beta$-catenin and $\mathrm{Wnt}$ signaling to thyroid cancer progression.

Indeed, aberrant $\beta$-catenin expression in PTC is positively correlated with loco-regional recurrence and distant metastasis (19). Moreover, high expression of $W N T 10 A$ in PTC has been reported to increase $\beta$-catenin signaling activation (20). Data extracted from 50 pairmatched PTC samples from TCGA database shows increased expression of $W N T 10 A, C T N N B 1$ and $C C N D 1$, while AXIN2 is downregulated (Figure 2), indicating that Wnt signaling is activated in PTC.

Modulation of $\mathrm{Wnt} / \beta$-catenin signaling pathway would be a potential adjuvant approach to treat aggressive thyroid cancer. Indeed, knock-down of the overexpressed $\beta$-catenin using shRNA blocks cell proliferation and induces senescence in RAS-mutated ATC cell lines (21). On the other hand, modulating Wnt signaling antagonist DKK1 has shown promising effects in vitro (22). DKK1 is downregulated in $\mathrm{PTC}$, and its restoration reduced thyroid cancer cell viability and migration while induced apoptosis. Moreover, several drugs that target Wnt signaling pathway are under clinical-trials, however none have been approved for clinical use to date $(6,23)$.

Thus, identification of novel miRNA deregulated in aggressive PTC that modulate Wnt signaling uncovered an additional layer of post-transcriptional regulation by miRNA; and miRNAs emerge as a new potentially targetable molecules for an adjuvant therapy in the future.

\section{Acknowledgments}

Funding: The authors would like to thank FAPESP and $\mathrm{CNPq}$ for financial support.

\section{Footnote}

Conflicts of Interest: The authors have no conflicts of interest to declare.

Ethical Statement: The authors are accountable for all aspects of the work in ensuring that questions related 


\section{Page 4 of 4}

to the accuracy or integrity of any part of the work are appropriately investigated and resolved.

Open Access Statement: This is an Open Access article distributed in accordance with the Creative Commons Attribution-NonCommercial-NoDerivs 4.0 International License (CC BY-NC-ND 4.0), which permits the noncommercial replication and distribution of the article with the strict proviso that no changes or edits are made and the original work is properly cited (including links to both the formal publication through the relevant DOI and the license). See: https://creativecommons.org/licenses/by-nc-nd/4.0/.

\section{References}

1. Celano M, Rosignolo F, Maggisano V, et al. MicroRNAs as Biomarkers in Thyroid Carcinoma. Int J Genomics 2017;2017:6496570.

2. Peng $Y$ and Croce CM. The role of MicroRNAs in human cancer. Signal Transduct Target Ther 2016;1:15004.

3. Yu S, Cao S, Hong S, et al. miR-3619-3p promotes papillary thyroid carcinoma progression via Wnt/betacatenin pathway. Ann Transl Med 2019;7:643.

4. Agarwal V, Bell GW, Nam JW, et al. Predicting effective microRNA target sites in mammalian mRNAs. Elife 2015. doi: 10.7554/eLife.05005.

5. Steinhart Z, Angers S. Wnt signaling in development and tissue homeostasis. Development 2018. doi: 10.1242/ dev.146589.

6. Zhan T, Rindtorff N, Boutros M. Wnt signaling in cancer. Oncogene 2017;36:1461-73.

7. Sastre-Perona A, Santisteban P. Role of the wnt pathway in thyroid cancer. Front Endocrinol (Lausanne) 2012;3:31.

8. Vandernoot I, Haerlingen B, Trubiroha A, et al. Enhanced canonical Wnt signaling during early zebrafish development perturbs the interaction of cardiac mesoderm and pharyngeal endoderm and causes thyroid specification defects. BioRxiv 2019. doi: https://doi.org/10.1101/2019.12.19.880815.

9. Gilbert-Sirieix M, Makoukji J, Kimura S, et al. Wnt/ beta-catenin signaling pathway is a direct enhancer of thyroid transcription factor- 1 in human papillary thyroid carcinoma cells. PLoS One 2011;6:e22280.

10. Zhang X, Li M, Zuo K, et al. Upregulated miR-155 in papillary thyroid carcinoma promotes tumor growth by targeting APC and activating Wnt/beta-catenin signaling. J Clin Endocrinol Metab 2013;98:E1305-13.

11. Wen Q, Zhao J, Bai L, et al. miR-126 inhibits papillary thyroid carcinoma growth by targeting LRP6. Oncol Rep
Fuziwara and Kimura. miRNA and Wnt signaling in thyroid cancer

2015;34:2202-10.

12. Zhou AD, Diao LT, Xu H, et al. beta-Catenin/LEF1 transactivates the microRNA-371-373 cluster that modulates the $\mathrm{Wnt} /$ beta-catenin-signaling pathway. Oncogene 2012;31:2968-78.

13. Boos LA, Schmitt A, Moch H, et al. MiRNAs Are Involved in Tall Cell Morphology in Papillary Thyroid Carcinoma. Cancers (Basel) 2019. doi: 10.3390/cancers11060885.

14. Landa I, Ibrahimpasic T, Boucai L, et al. Genomic and transcriptomic hallmarks of poorly differentiated and anaplastic thyroid cancers. J Clin Invest 2016;126:1052-66.

15. Xu B, Ghossein R. Genomic Landscape of poorly Differentiated and Anaplastic Thyroid Carcinoma. Endocr Pathol 2016;27:205-12.

16. Kurihara T, Ikeda S, Ishizaki Y, et al. Immunohistochemical and sequencing analyses of the Wnt signaling components in Japanese anaplastic thyroid cancers. Thyroid 2004;14:1020-9.

17. Garcia-Rostan G, Tallini G, Herrero A, et al. Frequent mutation and nuclear localization of beta-catenin in anaplastic thyroid carcinoma. Cancer Res 1999;59:1811-5.

18. Sadot E, Geiger B, Oren M, et al. Down-regulation of beta-catenin by activated p53. Mol Cell Biol 2001;21:6768-81.

19. Cho SW, Kim YA, Sun HJ, et al. Therapeutic potential of Dickkopf-1 in wild-type BRAF papillary thyroid cancer via regulation of beta-catenin/E-cadherin signaling. J Clin Endocrinol Metab 2014;99:E1641-9.

20. Dong T, Zhang Z, Zhou W, et al. WNT10A/betacatenin pathway in tumorigenesis of papillary thyroid carcinoma. Oncol Rep 2017;38:1287-94.

21. Sastre-Perona A, Riesco-Eizaguirre G, Zaballos MA, et al. beta-catenin signaling is required for RAS-driven thyroid cancer through PI3K activation. Oncotarget 2016;7:49435-49.

22. Cho SW, Lee EJ, Kim H, et al. Dickkopf-1 inhibits thyroid cancer cell survival and migration through regulation of beta-catenin/E-cadherin signaling. Mol Cell Endocrinol 2013;366:90-8.

23. Harb J, Lin PJ, Hao J. Recent Development of Wnt Signaling Pathway Inhibitors for Cancer Therapeutics. Curr Oncol Rep 2019;21:12.

Cite this article as: Fuziwara CS, Kimura ET. How does microRNA modulate $W n t / \beta$-catenin signaling in thyroid oncogenesis? Ann Transl Med 2020;8(6):266. doi: 10.21037/ atm.2020.02.152 